\title{
Study on Consolidation Calculation of the Concrete-cored Sand-gravel Piles Composite Foundation
}

\author{
Yunfei GUAN ${ }^{1, a}$ Yanwei YANG ${ }^{2, b}$ Xiaomei $\mathrm{LI}^{1, c}$ Wenxuan $\mathrm{LI}^{1, \mathrm{~d}}$ \\ ${ }^{1}$ Geotechnical Engineering Department, Nanjing Hydraulic Research Institute, Nanjing, China \\ ${ }^{2}$ China railway siyuan survey and design group co.,Ltd,Kunming,China

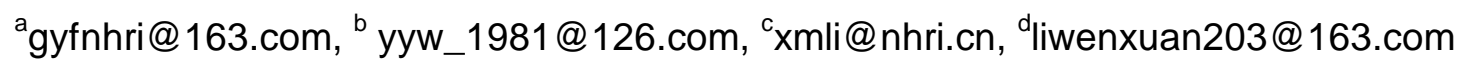

Keywords: composite foundation, concrete-cored sand-gravel piles, consolidation

Abstract: The new style composite foundation is composed of the concrete-cored sand-gravel pile, the soil between piles and the cushion. According the work condition under the embankment, and considering the annular drainage section of sand-gravel columns composite foundation, the control equation and analytical solution of composite foundation was obtained, the average degree of consolidation were given. Finally the comparison between the calculated results and the filed measured data showed that the calculated excess pore water pressure, the degree of consolidation and the settlement-time relationship were consistent with those of field data respectively.

\section{Introduction}

The composite foundation with concrete-cored sand-gravel pile, which is composed of the concrete-cored sand-gravel pile, the geosynthetic cushion and the foundation soil, is a new technology with the advantages of the high strength prefabricated concrete pile and the better drainage and consolidation characteristics of the sand-gravel piles [1,2],

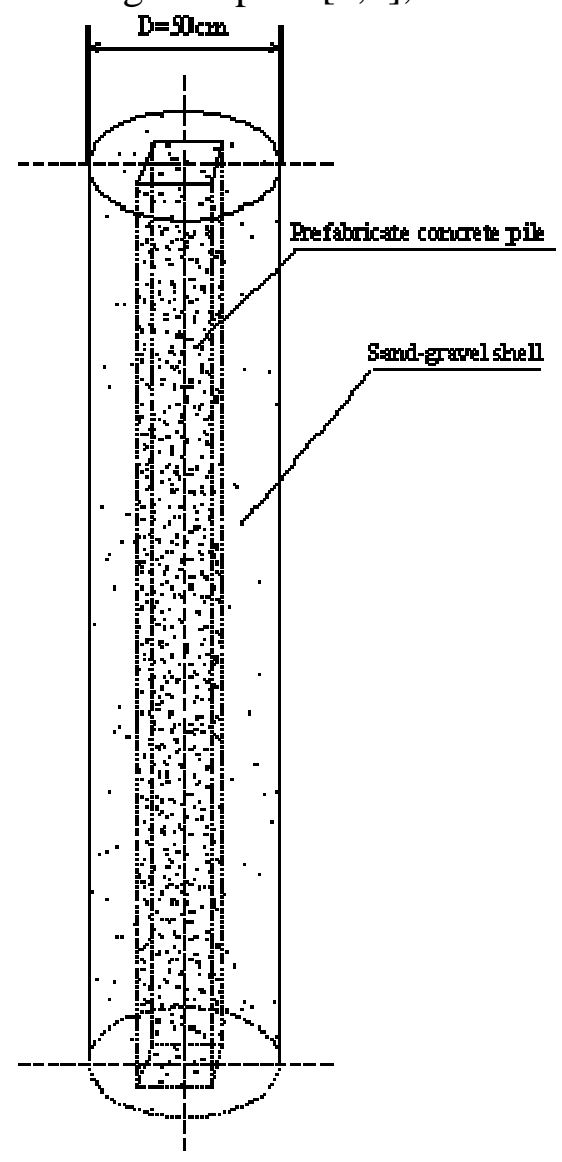

Figure1. Schematic diagram of concrete-cored sand-gravel piles

The structural type of concrete-cored sand-gravel pile composite foundation, which is shown in figure 1. In this proposed composite foundation, prefabricated concrete pile is vertical reinforcement, 
sand-gravel shell is vertical drainage body and accumulation earthwork is pre-loading. Under the load, the sand-gravel shell speeds up the consolidation of soil between piles in construction and preloading periods to reduce the post-construction settlement in applied periods.

Currently there are many research results about consolidation problem of composite foundation under embankment $[3,4,5]$, but most of them are aimed at flexible pile, such as gravel pile and mixing pile, and mostly follow the assumption of equal strain. As we known, the discrete material pile (such as gravel pile), flexible piles (such as mixing pile) are substantially equal strain under embankment, but equal strain assumption is difficult to meet rigid piles (such as concrete pile) composite foundation.

Excess pore water pressure in inter-pile soil is caused by the embankment load on the inter-pile soil. As for the concrete-cored sand-gravel pile, if the embankment load shared by the unit body combined of annular gravel pile and inter-pile soil can be obtained, its consolidation calculation is transformed into the consolidation problem of discrete material pile composite foundation. So the difficulty of consolidation calculation of concrete-cored sand-gravel pile composite foundation is how to determine the sharing load of the pile and the soil. In addition, annular gravel pile, as the vertical drainage channel, its unique annular drainage channel should be considered in the consolidation calculation.

This paper according to the load transfer law of concrete-cored sand-gravel pile composite foundation load, transform the consolidation calculation of concrete-cored sand-gravel pile composite foundation to that of annular gravel pile foundation with equal strain.

\section{Consolidation equation of reinforced area}

\section{Calculation diagram}

The element combined of annular gravel pile and inter-pile soil is taken as the calculation model, which shown in Figure2. $H$ is the soil thickness of reinforcement area, $E_{w}$ and $E_{s}$ are the compression modulus of inter-pile soil and gravel pile respectively; $r_{w}$ is sand gravel pile radius; $r_{c}$ is core pile radius; $r_{e}$ is the drainage affected zone radius; $r_{s}$ is the radius of the disturbed zone; $\bar{\sigma}$ is the average load of sand gravel pile and inter-pile soil. $k_{h}, k_{s}$ are the horizontal permeation coefficient of inter-pile soil of undisturbed areas and disturbed areas respectively; $k_{w}, k_{v}$ are the vertical permeability coefficient of inter-pile soil and the permeability coefficient of sand-gravel pile respectively.

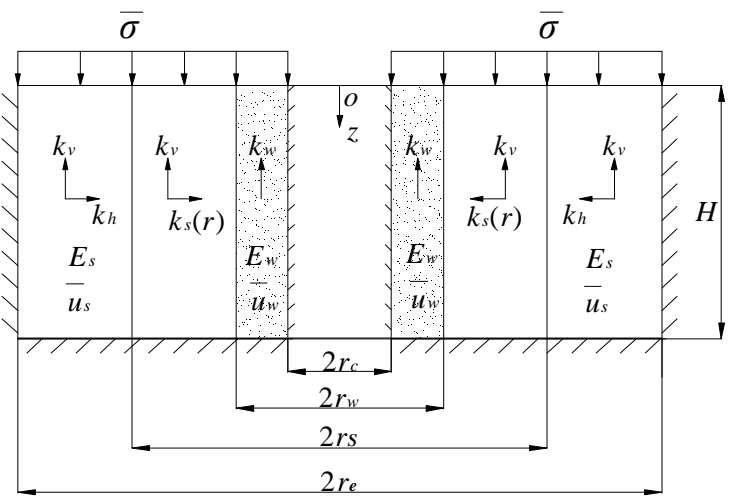

Figure2. Simplified Analysis model

\section{Consolidation equation}

In this paper, the consolidation calculating method are based on the following assumptions:

(1)The equal strain assumption of core piles and inter-pile soil does not apply to this problem, let G as the load sharing ratio of core pile body;

(2) The equal strain assumption of annular sand piles and inter-pile soil holds, annular sand piles and soil are subjected to the lateral restraint, and the vertical deformation is equal.

(3) Except the horizontal permeation coefficient between undisturbed areas and disturbed areas are different, other properties are the same.

(4) The seepage of water in the soil obeys Darcy's law.

(5) Load is applied instantaneously, and the additional pressure in the composite foundation caused by the load is constant along the depth. 
(6) Using the assumption that the flow around the piles is continuous, and ignoring the radial seepage of the annular gravel pile. Accordingly, in any depth $\mathrm{z}$, the water volume flowing from the inter-pile soil to the gravel pile is equal to the increment of the upward flow in the gravel pile.

$$
\left.\left[2 \pi r d z \frac{k_{s}}{\gamma_{w}} \frac{\partial u_{s}}{\partial r}\right]\right|_{r=r_{w}}=-\pi\left(r_{w}^{2}-r_{c}^{2}\right) d z \frac{k_{w}}{\gamma_{w}} \frac{\partial^{2} \bar{u}_{w}}{\partial z^{2}}
$$

Assuming that the instantaneous total load applied on the ground is $\pi r_{e}^{2} \bar{p}$, the load sharing ratio of the core pile is $G$. The total load shared by both inter-pile soil and annular gravel pile is:

$$
\sigma_{\text {total }}=\pi r_{e}^{2} \bar{p}(1-G)
$$

Accordingly,the average load shared by inter-pile soil and annular gravel pile is:

$$
\bar{\sigma}=\frac{r_{e}^{2} \bar{p}(1-G)}{\left(r_{e}^{2}-r_{c}^{2}\right)}
$$

For the unit body combined of annular gravel pile and inter-pile soil, by the load balance conditions and the basic assumptions,we get the following foumula,

$$
\frac{\partial \varepsilon_{v}}{\partial t}=-\frac{n^{2}-m^{2}}{E_{s}\left[n^{2}-1+\left(1-m^{2}\right) Y\right]} \frac{\partial \bar{u}}{\partial t}
$$

Where,

$n=\frac{r_{e}}{r_{w}}, m=\frac{r_{c}}{r_{w}}, s=\frac{r_{s}}{r_{w}}, Y=\frac{E_{w}}{E_{s}}$

The consolidation equations of soil are:

$\frac{k_{s}}{\gamma_{w}} \frac{1}{r} \frac{\partial}{\partial r}\left[r \frac{\partial u_{s}}{\partial r}\right]+\frac{k_{v}}{\gamma_{w}} \frac{\partial^{2} \bar{u}_{s}}{\partial z^{2}}=-\frac{\partial \varepsilon_{v}}{\partial t} ; r_{w} \leq r \leq r_{s}$

$\frac{k_{h}}{\gamma_{w}} \frac{1}{r} \frac{\partial}{\partial r}\left[r \frac{\partial u_{s}}{\partial r}\right]+\frac{k_{v}}{\gamma_{w}} \frac{\partial^{2} \bar{u}_{s}}{\partial z^{2}}=-\frac{\partial \varepsilon_{v}}{\partial t} ; r_{s} \leq r \leq r_{e}$

The corresponding radial boundary conditions are given by

$$
r=r_{e}: \frac{\partial u_{s}}{\partial r}=0 ; \quad r=r_{s}: k_{s} \frac{\partial u_{s}}{\partial r}=k_{h} \frac{\partial u_{s}}{\partial r} ; \quad r=r_{w}: u_{s}=u_{w}=\bar{u}_{w}
$$

It is not difficult to get the following calculation formula about pore pressure.

$$
\bar{u}=\bar{u}_{w}+\frac{\gamma_{w} r_{e}^{2} F_{a}}{2 k_{h}}\left[\begin{array}{cc}
-\frac{n^{2}-1}{E_{s}\left[n^{2}-1+\left(1-m^{2}\right) Y\right]} \frac{\partial \bar{u}}{\partial t} \\
+\frac{k_{v}}{\gamma_{w}}\left(\frac{\partial^{2} \bar{u}}{\partial z^{2}}-\frac{1-m^{2}}{n^{2}-m^{2}} \frac{\partial^{2} \overline{u_{w}}}{\partial z^{2}}\right)
\end{array}\right]
$$

Where,

$$
\begin{aligned}
& F_{a}=\left(\ln \frac{n}{s}+\frac{k_{h}}{k_{s}} \ln s-\frac{3}{4}\right) \frac{n^{2}}{n^{2}-1}+\frac{s^{2}}{n^{2}-1}\left(1-\frac{k_{h}}{k_{s}}\right)\left(1-\frac{s^{2}}{4 n^{2}}\right)+\frac{k_{h}}{k_{s}} \frac{1}{n^{2}-1}\left(1-\frac{1}{4 n^{2}}\right) \\
& \bar{u}=\bar{u}_{w}-A \frac{\partial^{2} u_{w}}{\partial z^{2}}
\end{aligned}
$$

In the formula, $\mathrm{A}$ is a positive constant, and its expression is:

$A=\frac{1-m^{2}}{n^{2}-m^{2}} \frac{r_{e}^{2} k_{w} F_{a}}{2 k_{h}}$

Then,the the governing equation of $\bar{u}_{w}$ can be obtained from formula (7) and (9).

$B \frac{\partial^{4} \bar{u}_{w}}{\partial z^{4}}+C \frac{\partial^{2} \bar{u}_{w}}{\partial z^{2}}+A \frac{\partial^{3} \bar{u}_{w}}{\partial t \partial z^{3}}-\frac{\partial \bar{u}_{w}}{\partial t}=0$ 
where $B, C$ are constant, the expression is as follows:

$$
\begin{aligned}
& B=-\frac{c_{v}\left[n^{2}-1+\left(1-m^{2}\right) Y\right]\left(1-m^{2}\right) r_{e}^{2} k_{w} F_{a}}{2\left(n^{2}-1\right)\left(n^{2}-m^{2}\right) k_{h}} \\
& C=\frac{c_{h} k_{w}\left[n^{2}-1+\left(1-m^{2}\right) Y\right]\left[\left(1-m^{2}\right)+\left(n^{2}-1\right) \frac{k_{v}}{k_{w}}\right]}{\left(n^{2}-1\right)\left(n^{2}-m^{2}\right) k_{h}}
\end{aligned}
$$

As shown in Figure 3, the bottom surface of the unit is not permeable, the top surface is permeable, and the boundary condition of the equations are:

$$
\left\{\begin{array}{l}
z=0: \bar{u}(z, t)=0, \bar{u}_{w}(z, t)=0 \\
z=H: \frac{\partial \bar{u}(z, t)}{\partial z}=0, \frac{\partial u_{w}(z, t)}{\partial z}=0
\end{array}\right.
$$

At the initial time, the total additional stress of the unit body is born by the pore water in the inter-pile soil and gravel piles, the effective stress is equal to zero,

$$
t=0: \quad \varepsilon_{v}=\varepsilon_{z}=0, \quad \bar{\sigma}_{s}=\bar{u}_{s}, \bar{\sigma}_{w}=\bar{u}_{w}, \quad \bar{u}(z, 0)=\bar{\sigma}(z, 0)
$$

\section{The solution of control equation}

From the governing equation, boundary condition and initial condition, the excess pore water pressure in the sand piles and the unit body are respectively:

$$
\begin{aligned}
& \bar{u}_{w}(z, t)=\sum_{a=1}^{\infty} \frac{2 \bar{\sigma}}{M\left[1+A\left(\frac{M}{H}\right)^{2}\right]} \sin \left(\frac{M}{H} z\right) e^{-\beta_{a} t} \\
& \bar{u}(z, t)=\sum_{a=1}^{\infty} \frac{2 \bar{\sigma}}{M} \cdot \sin \frac{M z}{H} \cdot e^{-\beta_{a} t}
\end{aligned}
$$

The expression formula of consolidation degree can be described as:

$$
U_{p}(t)=1-\sum_{a=1}^{\infty} \frac{2}{M^{2}} e^{-\beta_{a} t}
$$

\section{Engineering example}

In order to verify the method in this paper, A field test for the concrete-cored sand-gravel pile composite foundation, in a section of Zhen-Li expressway bridge approach [7], is calculated and compared with the measured data.The design height of embankment is $6 \mathrm{~m}$, the thick of surcharge preloading earthwork is $2 \mathrm{~m}$, the composite pile length was $22 \mathrm{~m}$. The space of the pile was $2.1 \mathrm{~m}$. soft soil thickness of $26.5 \mathrm{~m}$. According to the measured load of inter-pile soil, calculating the consolidation degree and pore pressure by the method in this paper.

(1) Pore pressure

Figure 3 shows the excess pore pressure dissipation curve, which got from the calculation of $2.0 \mathrm{~m}$ depth by formula (16) and field measurement.The results show that the pore pressure calculated by the theoretical method is similar to the dissipation law of field measurement.

(2) Consolidation degree

The consolidation degree development law of the reinforcement area is compared with the consolidation degree of theoretical calculation as shown in Figure 4. As we can see, the consolidation degree development law and consolidation degree got from calculation are close to the field measured value. 


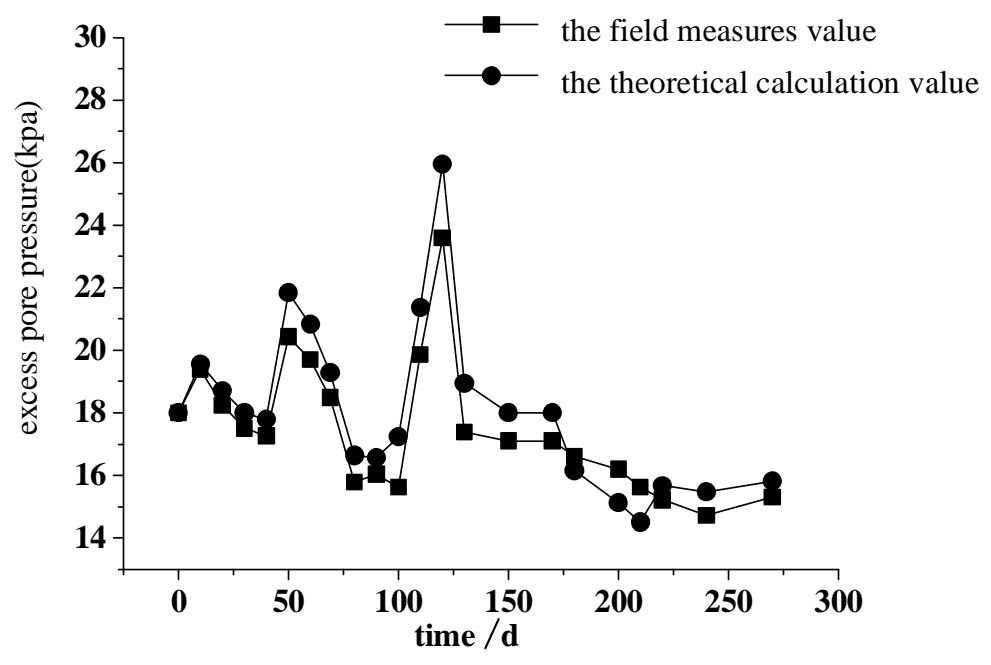

Figure3. Variation of excess pore pressure with time

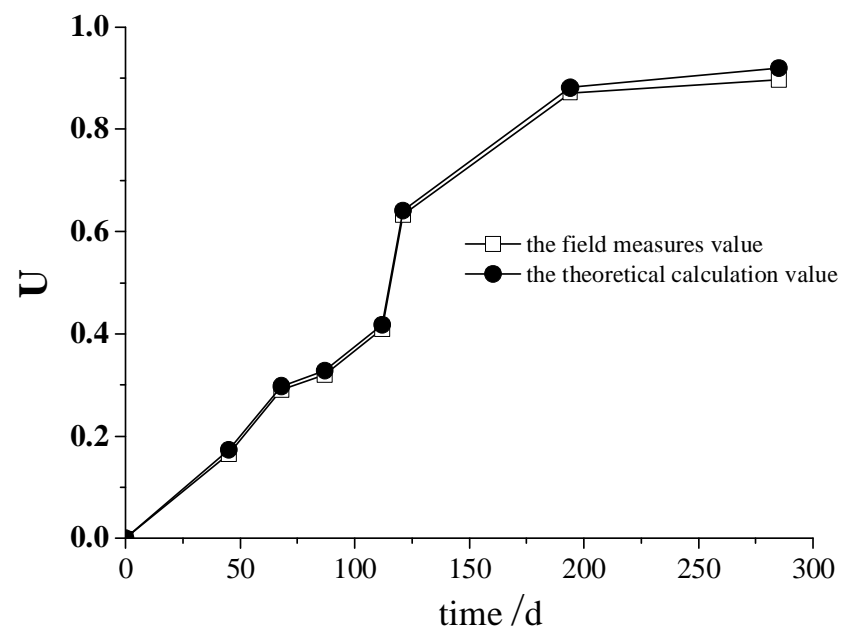

Figure4. Variation of consolidation degree of improved zone with time

\section{Conclusions}

(1) This concrete-cored sand-gravel pile composite foundation consolidation calculation method established in this paper, considering the annular drainage channel of gravel pile and thestress concentration of pile body, is closer to the actual working condition compared with the previous calculation method.

(2) Verified the rationality of the method in this paper by the calculation of engineering example, the calculated results are in good agreement with the measured data.

(3) In the process of concrete-cored sand-gravel pile composite foundation reinforcement, the consolidation of inter-pile soil and the soil arching effect of embankment filled soil occur at the same time, and influence each other, it also relates to the interaction among the core pile, the annular gravel pile and the inter-pile soil, which is very complicated. Hence, we still need the Further research about the load transfer mechanism, especially the reinforcement mechanism of embankment load.

\section{Acknowledgements}

This work was financially supported by Natural Science Foundation of China (51208321). 


\section{References}

[1] ZHAO Weibing, TANG Tongzhi, CAI Xin,et al.A new method of improving soft soil: composite foundation with Concrete-cored Sand-gravel Piles:China,Patent 200610037621.2.(2008)

[2] CHEN Junshen, ZHAO Weibing, Application of the Concrete- cored Sand-gravel Pile Composite Foundation Technology Treating Thick and Soft Foundation at Bridge Head.construction technology,Vol.36(2007),p,70

[3] XIE Kanghe. Present state anddevelopment of the study on the consolidation theory of thecomposite foundation.Foundation Treatment, Vol.4(1993),p, 1

[4] WANG Rui-chun. Analytical Studies on the Consolidation of Soft Cla-y Ground Improved by Vertical Drains or Granular Columns. Hangzhou: ZhejiangUniversity(2007)

[5] LU Mengmeng, XIE Kanghe, ZHANG Yuguo etal. Theoretical solution for consolidation of composite foundations considering construction disturbance and loading effect.Journal of Geotechnical Engineering, Vol.30(2008),p,549

[6]LIU Jifu.Analysis ofconsolidationofequal-strain composite ground under embankment.Chinese Journal of Rock Mechanics and Engineering. Vol.28(2009),p,3042

[7]CHEN Junsheng, TANG Tongzhi, ZHAO Weibing, et al.Field tests on composite foundation with concrete-coredsand-gravel piles. Chinese Journal of GeotechnicalEngineering, Vol.29(2007),p,957 